\title{
RAZÃO DOS ANIMAIS EM HUME E NOS CÉTICOS MODERNOS
}

Flávio Miguel de Oliveira Zimmermann*

\begin{abstract}
Resumo: O pensamento de Hume pode ser comparado ao dos céticos modernos em muitos aspectos. Com relação ao tópico da racionalidade dos animais, Hume parece seguir de perto a leitura de alguns céticos modernos e se afastar consideravelmente da de Descartes. Por outro lado, diferente de filósofos como Montaigne, Charron e La Mothe Le Vayer, Hume não tinha por finalidade colocar a racionalidade humana num nível próximo dos animais para apenas provar a fraqueza do intelecto diante do desconhecido, mas intentava comparar o nosso modo de proceder ao do animal para avaliar, com mais precisão, as suas teorias acerca da natureza humana. Neste artigo analiso o modo como os primeiros céticos da modernidade trataram da questão da razão dos animais e o comparo com as ideias de Hume sobre o assunto, sem deixar de mencionar as contribuições de Descartes e de Pierre Bayle.
\end{abstract}

Palavras-chave: ceticismo, razão dos animais, Hume, Descartes, Montaigne.

A discussão acerca da racionalidade dos animais está presente em toda história da filosofia. Em certas ocasiões ela serviu e serve para contribuir para o debate ético acerca dos direitos dos seres sensientes, visto que racionalidade nesses casos está ligada à consciência que um ser pode ter de sentir dor e prazer. Em outros momentos, o debate é de grande utilidade na tentativa de compreender o próprio homem e sua forma de raciocinar, comparando o seu comportamento e medindo a sua capacidade de entendimento com a dos animais.

Embora o debate ético, nesses casos, esteja frequentemente relacionado ao epistemológico, de maneira que torna-se difícil tratar de um sem fazer menção ao outro, este texto procura se concentrar na controvérsia acerca do entendimento do animal suscitada pelos filósofos modernos e sua relação com o ceticismo. Primeiramente, retratando de forma breve o contexto em que tais preocupações surgiram, especialmente entre os céticos do início da modernidade, tais como Montaigne, Charron e La Mothe Le Vayer para analisar a maneira como esses autores refletem sobre a posição do homem e do animal em suas filosofias. Em seguida, apresentando a tese cartesiana do animal-máquina e seus pontos de divergência com relação aos céticos acerca desse tema, além das críticas de Pierre Bayle a ambas as hipóteses. Por fim, apresentando a visão de Hume sobre a controvérsia e comparando as suas ideias com as dos céticos e a de Descartes.

\footnotetext{
* Professor da Universidade Federal da Fronteira Sul (UFFS)
} 
A filosofia de Hume se aproxima em muitos aspectos da dos céticos acima mencionados. A ênfase nesse caso diz respeito ao que se refere à defesa da existência de uma razão dos animais e à equiparação da razão humana com a desses seres. Para esse fim, tanto Hume quanto Montaigne, Charron e Le Vayer fazem apelo constante à natureza para tentar compreender o conhecimento humano e adotam um posicionamento crítico com relação a qualquer tipo de explicação que tenha como fim privilegiar a racionalidade humana em detrimento da do animal. Nesse aspecto, Hume se afasta em grande medida do pensamento cartesiano, que procura representar a razão humana como característica distintiva no homem. Por outro lado, o procedimento de investigação humeano, derivado de métodos mais bem elaborados da filosofia moderna, o afasta de algumas conclusões generalistas e ousadas dos céticos do início da modernidade sobre o comportamento e razão dos animais.

\section{Razão dos animais e ceticismo moderno}

Por volta dos séculos XVI e XVII, a explicação que predominava para justificar os movimentos, ações e reações dos animais vinha da teoria aristotélico-escolástica, isto é, de que as atividades e percepções dos animais devem-se a funções de uma alma não-corporal ${ }^{1}$. Para Aristóteles, todas as coisas vivas e animadas implicam a presença de uma alma, seja vegetativa, sensitiva ou racional - sendo essa última exclusiva dos seres humanos. Outro modo de enfatizar a irracionalidade dos animais neste período vinha da teoria estóica, principalmente por meio da explicação de Agostinho².

O ponto de controvérsia a essas visões no século XVII primeiro surgiu com os que George Boas chamou de "teriofilistas" ou, literalmente, "amantes dos animais" (apud Harrison 12), cujos principais representantes seriam Pierre Charron e Marin Cureau de la Chambre, ambos inspirados nos escritos de Michel de Montaigne do final do século XVI. Harrison nos lembra que a base dos teriofilistas para suas argumentações em defesa de uma visão contemplativa e de respeito com relação aos animais vem do estoicismo, ao sustentarem a tese de que "viver corretamente é viver de acordo com a natureza". De fato, em muitas passagens de Montaigne e de seus seguidores, os animais aparecem como modelos, como uma espécie de professores para os homens, visto que estão mais próximos 
da natureza do que nós. Porém, é preciso notar que, além da aproximação dessa tese presente nos filósofos do início da modernidade com a doutrina dos estóicos, a sua relação pode ser feita tendo como foco a influência do ceticismo nos escritos de Montaigne (15331592) e Charron (1541-1603), além de François de La Mothe Le Vayer (1588-1672). Isso é o que veremos a seguir.

Na sua "Apologia de Raimundo de Sabunde", Montaigne se põe a atacar a vaidade da razão humana, o seu propósito de querer tudo explicar e a noção de superioridade do homem sobre os demais seres do universo. Assim que estipula o objeto de discussão na primeira parte do ensaio, inicia uma longa comparação entre o homem e os animais. $\mathrm{O}$ texto é carregado de inúmeras anedotas e histórias antigas a respeito dos modos de instrução e comportamento dos bichos.

Entre outras observações, o autor nota que podemos conhecer alguns dos estados emocionais dos animais, visto que eles nos ameaçam, nos fazem pedidos e se comprazem conosco assim como nós fazemos com eles: os animais não só raciocinam ao reconhecer a nossa voz (Montaigne 20, p. 262), mas também amam e defendem seus donos, chegando a agredir estranhos que os ofendem (Montaigne 20, p. 264). Alguns até conduzem cegos por caminhos movimentados, desviando-os dos perigos e chegando até a sacrificar a sua própria comodidade e segurança em benefício do seu dono (Montaigne 20, p. 260). A que se explicaria tais atitudes, pensa, senão pelo fato de que os animais são capazes de criar laços de afeição por nós?

Com relação à linguagem, a tese de Montaigne é a de que há comunicação entre os próprios animais, seja por meio da voz ou de gestos: "Pelo latido do cão, o cavalo conhece a sua cólera", diz ele (Montaigne 20, p. 254). Eles compreendem de maneira diferente da nossa língua falada, é verdade, mas não é também por gestos e tons de voz que uma criança reage no seu meio? E, assim como elas, Montaigne chega a levantar a possibilidade de que os animais possam ser instruídos, visto que os melros, corvos, pegas e papagaios podem falar como nós (Montaigne 20, p. 260).

Os exemplos continuam e casos mais refinados são oferecidos: as andorinhas e aranhas constroem suas moradas de modo tão calculado e as abelhas possuem uma organização social tão complexa, que seria um grande erro não atribuir-lhes algum tipo de inteligência (Montaigne 20, p. 254). Suposições e hipóteses mais abstratas e ousadas, que 
ultrapassam muito a mera observação do comportamento animal também são expostas para análise. Pois é possível supor que os animais sejam dotados de algum conhecimento interior e inacessível a nós, de modo que, assim como nós os julgamos irracionais, eles podem supor que nós é que somos irracionais (20, p. 253). Com a intenção de menosprezar os que julgam a ciência humana superior às demais, Montaigne conjectura que os atuns também têm conhecimento de geometria, aritmética e astronomia, quando se reúnem em forma de cubo ou quando se escondem no solstício do inverno até o próximo equinócio (Montaigne 20, p. 270). Além disso, seguindo Lucrécio, o filósofo supõe que os animais sonham e imaginam coisas da mesma forma que nós, como o cão, que persegue a lebre em sonhos e grunhe para homens que não existem (20, pp. 271-2). Fazendo uso do raciocínio, eles são capazes até de presumir acontecimentos futuros, como as formigas, que fazem previsões para as estações estéreis do ano e os grous e andorinhas, que antecipam a mudança do tempo (Montaigne 20, p. 256 e 264).

Montaigne preza o conhecimento dos animais de tal maneira que chega a desconfiar que alguns deles têm noções de religião. Os elefantes, que não têm qualquer instrução, aparentemente oram e, embora não tenhamos sinais de que outros bichos façam o mesmo, não podemos nos pronunciar de forma negativa (Montaigne 20, p. 263). É certo, conclui, que não podemos interpretar todas essas evidências como obras do acaso ou da natureza animal, pois se os animais agem de modo tão semelhante a nós, e às vezes chegam até a ultrapassar as nossas obras devido ao capricho e exatidão de suas realizações, como poderíamos atribuir a eles uma posição inferior a nossa ou dizer que agem meramente baseados num instinto? (Montaigne 20, p. 255).

Outras contribuições a esse ponto de vista chegaram de Pierre Charron, em seu livro Da Sabedoria (De la Sagesse). Charron estudou com Montaigne e tinha uma amizade muito próxima a ele ${ }^{3}$, sendo o seu principal discípulo e divulgador de suas ideias naquele tempo, bem como do seu ceticismo. No caso da racionalidade dos animais, as teses de ambos os autores assemelham-se tanto que em certas situações pode-se encontrar paráfrases de Charron dos textos de Montaigne. Os exemplos de Montaigne sobre os sonhos e grunhidos do cão, sobre o cavalo que reconhece quando o cão está raivoso, da similaridade entre a criança e o animal na forma de falar e de se expressar, das relações de afetividade do animal com o seu dono são todos repetidos por ele (Charron 5, pp. 60-1 e 66), e a sua 
conclusão a respeito da razão dos animais não poderia ser diferente: tudo isso não se deve a alguma inclinação ou instinto natural dos bichos, pois eles raciocinam, embora mais imperfeitamente do que o homem.

Eles são inferiores ao homem da mesma forma que uns homens são inferiores a outros, continua. Porém, há mais diferença de grau entre um homem e outro do que entre um homem e um animal (Charron 5, pp. 66 e 175). Há coisas que eles são melhores do que nós e há coisas que nós os ultrapassamos. Por exemplo, eles têm mais suficiência, subtilidade e engenho do que o homem comum, enquanto nós temos as faculdades do raciocínio, do discurso, da disciplina, do juízo e da prudência. Entretanto, é visível que os bichos também concluem os universais a partir do singular, pois da relação com um homem conhecem todos, além de saber somar, dividir e distinguir o bom do mau (Charron 5, p. 63).

Outra vantagem que o homem pretende ter sobre os animais é a de comandá-los e domesticá-los. Mas isso é uma quimera, mostra Charron, pois os homens temem os bichos mais do que o inverso. E se pensam que são mais livres, se enganam ao ver que os bichos não escravizam seus descendentes nem pela força nem de forma voluntária como nós ${ }^{4}$. Se pensam ainda que os bichos são passíveis de servir de alimento para nós, os bichos também nos matam e nos comem e, além disso, o homem pode servir de alimento para o seu próprio semelhante! Por fim, há mais um aspecto em que os animais nos ultrapassam, embora pensemos ocorrer o contrário, que é com relação à virtude. Pois o reconhecimento, a amizade, a fidelidade, a magnanimidade são características mais vivas e expressas nos bichos do que nos homens, já que eles seguem mais consistentemente a natureza e não se entregam aos vícios criados pelo homem. Em um dos seus exemplos, ele relata que o cão de Lisímaco ficara sobre o leito do mestre sem comer nem beber até que acabou se jogando ao fogo em que o corpo do mestre foi queimado ${ }^{5}$ (Charron 5, pp. 67-9).

Outros autores modernos inspirados pelo ceticismo argumentaram a partir desse mesmo ponto de vista, como Pierre Gassendi nas Dissertações em forma de paradoxos contra os aristotélicos, livro II, dissertação VI e François de La Mothe Le Vayer. Este último é mais significativo aqui e escreveu uma obra vasta em torno de temas da filosofia cética; muitos deles bem próximos ao pensamento de Montaigne, sem excluir a questão da razão dos animais. La Mothe Le Vayer, porém, parece ter em mente outros propósitos do que simplesmente mostrar a fraqueza da razão humana ao compará-la com a dos animais. 
Ele geralmente apresenta a tese da razão dos animais para contrapor a visão aristotélica predominante além de demonstrar a relatividade de todo conhecimento e ciência. Para esse autor, de modo mais claro do que em Montaigne e Charron, a doutrina da razão dos animais aparece como mais uma possibilidade, mais uma hipótese a ser levada em consideração pela ciência da sua época, embora, como mostraremos a seguir, ela também seja útil para o menosprezo da razão humana.

No "Diálogo sobre as qualidades raras e eminentes dos asnos desta época", que consta na sua obra mais conhecida, os Diálogos feitos à imitação dos antigos, ele levanta a hipótese de que os animais, assim como os homens, vêem Deus à sua própria imagem e semelhança: "a toupeira imagina um deus cego, a águia um deus voador, o delfim algum tritão batendo nas águas” (La Mothe le Vayer 17, tomo I, p. 277).

No "Discurso para mostrar que as dúvidas da filosofia cética são de grande utilidade nas ciências", depois de mostrar como os animais são bem tratados em várias passagens da Bíblia, afirma, como Charron, que não há maior diferença entre um homem e outro do que entre um homem e um animal. Na mesma parte comenta sobre animais que vivem em comunidade, como os narrados por Vasseur Beaplan na Ucrânia, além das abelhas e das formigas (La Mothe le Vayer 18, p. 59-61). O seu propósito, com esses exemplos, é o de mostrar que todas as opiniões da física, como a tese da nossa superioridade com relação aos animais, são problemáticas, visto que essa admite tanta exceção.

No Opúsculo ou Pequeno Tratado Cético, ele questiona a ideia de que o homem, enquanto animal racional, estaria em vantagem com relação aos demais, indicando que a nossa diferença com relação aos animais seria apenas de grau - exceção feita à questão da imortalidade da alma (La Mothe le Vayer 15, pp. 121-3). Ainda nos Solilóquios Céticos ele cita Galeno para mostrar que o desejo de saber, característica tão distinta no homem, encontra-se também nos animais (La Mothe le Vayer 16, pp. 05-6). Se dissermos, portanto, que nós diferimos do resto dos animais por causa da nossa ciência, podemos encontrar no próprio Aristóteles que essa é um privilégio de Deus somente e o melhor critério que podemos encontrar para nos diferenciar dos animais é a ignorância cética, já que eles não sabem que ignoram, assim como nós o sabemos (La Mothe le Vayer 17, tomo II, p. 28).

Exemplos como esses levantados por tais autores indicam que a questão da razão dos animais ocupa um papel importante em suas filosofias. Embora seja discutível se um cético 
como La Mothe Le Vayer possa dar o seu assentimento a uma tese filosófica como a da racionalidade dos animais, é visível pelas passagens acima que ela serve de argumento para fundamentar as suas teses céticas. O ponto de partida do ceticismo moderno é o de rebaixar a razão humana, expor as suas contradições e evidenciar que toda ciência humana com pretensão de atingir a verdade não passa de orgulho e vaidade da razão. Uma das formas encontradas para demonstrar isso está nos exemplos e indícios de que os animais também raciocinam e sentem o mundo de modo diferente, e em determinados casos, pensam de forma até mais sofisticada do que a nossa. Essa suposição serve também para atacar a ciência escolástica que se baseava na concepção de que o homem difere dos demais seres em espécie, e não em grau.

Outro aspecto importante nessa comparação se encontra na crítica da concepção de que o universo tenha sido criado para o bem-estar dos homens. É o questionamento da visão antropomórfica de mundo atribuída à escolástica. Montaigne, seguindo o raciocínio de Xenófanes, levanta o problema: mas por que os animais também não poderiam pensar que o universo foi feito para eles? O pato poderia imaginar que o sol e a terra foram feitos para o seu bem-estar e que os ventos, as águas e até o próprio homem o servem (20, p. 304). La Mothe Le Vayer faz a mesma analogia, criticando os estóicos que se julgavam estar no centro do universo: baseado em Sexto Empírico, ele usa como contra-exemplo o gato que pensa que o rato e o camundongo foram feitos para engordá-lo (La Mothe le Vayer 17, vol. 2, p. 99 e 18, p. 58).

Percebe-se até aqui que a relação entre os homens e os animais realizada pelos filósofos renascentistas não se reporta somente ao pensamento estóico. Por um lado, e tratando-se mais precisamente de Montaigne e Charron, encontramos passagens inspiradas no estoicismo que visam aproximar o homem da natureza, dos bichos, do vulgo e do homem simples. Se os animais se encontram num estado mais puro que o nosso por não terem se desviado de sua condição natural, eles nos são uma espécie de modelo a ser seguido. Os bichos vivem mais livres, mais moderados e contentes, dentro dos limites impostos pela sua natureza, dizem Montaigne e Charron ${ }^{6}$. Já o homem, que tem a vantagem de utilizar-se do entendimento, acaba por outro lado se sujeitando a outros males: inconstância, irresolução, superstição (Charron 5, pp. 70-1 e Montaigne 20, p. 274). 
"Encontrei em meu tempo cem artesãos e cem lavradores mais sábios e mais felizes que reitores de universidade: e com aqueles eu prefiro me parecer" (Montaigne 20, p. 275).

Mas o elogio à vida natural e ao modo simples de viver vem acompanhado da crítica à razão; a razão que tem pretensão de verdade e que tudo quer dominar e corromper. Trazer para o debate o modo de pensar e de agir dos animais, para então elevá-lo ao mesmo nível de relevância que o do ser humano, serve para colocar em questão a razão humana, que julga ver o mundo de forma privilegiada. Aqui a inspiração principal vem do maior compilador do ceticismo antigo, Sexto Empírico.

Nos seu primeiro tropo cético do capítulo XIV das Hipotiposes Pirrônicas, Sexto compara as percepções humanas às dos animais, a fim de mostrar que as mesmas impressões aparecem diferentemente conforme as espécies, devido a fatores como origem de nascimento, formato, constituição e tamanho dos seus corpos e membros.

Seguindo a divisão dos estóicos, Sexto se propõe a verificar se os animais possuem, assim como nós, razão interna - que seria implantada na alma, como a possibilidade de escolher as coisas boas e evitar as más, além de esperteza, aquisição de virtudes e poder confortar seus próprios sentimentos - e externa, que se verifica por meio da expressão. $\mathrm{O}$ cão, analisa Sexto, demonstra ter noções de justiça, sendo até mesmo dotado de virtude, uma vez que guarda e protege valentemente seus amigos e benfeitores e repele os estranhos e malfeitores. Ele também escolhe o que é melhor para si, procura curar suas próprias dores e adquire sagacidades, como a de caçar. E, assim como Montaigne e Charron, mostra indícios de que eles sejam dotados de razão externa, isto é, de linguagem ${ }^{7}$. Pois percebemos uma certa uniformidade nos sons que o cão emite: quando ele quer que nos afastemos, ouvimos um determinado ruído, quando uivam, quando são espancados ou quando estão servis temos outros sons nos indicando o seu estado de espírito. E o fato de não entendermos as suas formas de expressão não significa que não se expressem, pois os estrangeiros também possuem um linguajar incompreensível a nós. Outro exemplo de Sexto utilizado por Montaigne é o de que os pássaros prevêem o futuro por meio dos seus cantos e outros sinais (Empiricus 9, pp. 18-22).

O propósito principal de Sexto, com esses exemplos, porém, é o de mostrar que as qualidades reais dos objetos exteriores não nos são acessíveis. Se as mesmas coisas aparecem de modo diferente aos animais, o cético conclui que devemos suspender o juízo 
com relação à verdadeira natureza dos objetos. Pois, se nós mesmos estamos envolvidos na disputa, não podemos julgar entre nossas impressões e as dos animais (Empiricus 9, p. 17). Os céticos modernos não se afastaram dessa ideia ao aproximarem as formas de percepção e compreensão humanas das dos animais para mostrar que o modo como traduzimos as nossas impressões e como fazemos inferências a partir delas não é uma concepção exclusiva ou privilegiada da humanidade. Somos, assim como os animais, determinados a apreender as aparências internas e externas de acordo com o nosso porte: limitados pelos nossos sentidos e entendimento, e o máximo que podemos fazer é conjecturar como as coisas seriam vistas ou sentidas por seres de aspectos diferentes.

Charron mostra que o cervo, a águia, o cão, a serpente, a tartaruga têm faculdades sensoriais mais aguçadas do que nós: o primeiro tem a audição, o segundo a visão, o terceiro o olfato, o quarto o paladar e o quinto o tato, embora alguns considerem o do homem superior neste último caso. Além disso, alguns animais podem ser dotados de algum outro sentido que desconhecemos, assim como há os que vivem sem um deles (5, pp. 83-6). Essa ideia aparece também em Montaigne (20, p. 345) e Gassendi (10, pp. 442-4).

\section{A hipótese cartesiana}

Na última metade do século XVII, a posição dos teriofilistas começa a ser fortemente questionada, como mostra Harrison (12). Primeiro, porque a ideia de "natureza" enquanto guia de moralidade passou a ser cada vez mais criticada e, segundo, porque as visões de mundo que sustentavam uma relação próxima entre o homem e a natureza entraram em crise. Seguir inclinações naturais, como fazem os bichos, é transformar o próprio homem em bicho, protestavam o padre Garasse e Pierre Chanet. As paixões deveriam, portanto, estar sob o controle da razão, defendiam os novos racionalistas. O filósofo mais conhecido que sistematicamente sustentou essa tese é René Descartes.

A hipótese de Descartes foi divulgada pela primeira vez na quinta parte do Discurso do Método, embora a sua formulação tenha sido feita anteriormente em $O$ Mundo ou Tratado da Luz, cuja publicação foi suprimida pelo autor. De acordo com a sua concepção, o comportamento dos animais pode ser explicado em termos puramente mecânicos, assim como são as ações inconscientes do ser humano. O autor mostra que, assim como uma 
cabeça continua a se mover involuntariamente após ter sido decepada, o cérebro pode agir automaticamente devido a influências do meio externo (como a luz, o odor, o sabor, o calor) e interno (como as paixões) sobre nós. Ao receber uma determinada informação, o cérebro transmite os espíritos animais ${ }^{8}$ aos músculos, que conduzem os ossos a se movimentarem, sem que haja nessa ação qualquer intervenção da vontade.

Se pudéssemos construir uma máquina com a mesma estrutura e aparência do animal irracional, imagina Descartes, não teríamos como diferenciá-la dos seres brutos. Mas, se encontrássemos uma semelhante a nós, teríamos dois meios para provar que não estamos tratando de seres humanos: o primeiro é que, ainda que esses seres possam articular palavras para demonstrar o que sentem ou para responder a alguma solicitação, jamais poderiam combinar racionalmente essas palavras a fim de dar sentido às suas ideias contrariando, assim, os exemplos de Montaigne sobre a fala dos melros, corvos, pegas e papagaios. Além disso, tais criaturas seriam dotadas apenas de órgãos distribuídos pelo seu corpo, e só poderiam agir em função deles, e não por algum conhecimento ou razão, diz Descartes (7, pp. 57-8).

Descartes parte de uma concepção dualista do universo, na qual existem duas substâncias criadas (por uma terceira, que é Deus, e que existe por si mesma): a substância corporal (res extensa) e a substância mental (res cogitans). A extensão, diz ele, é o principal atributo da substância corporal e pensamento constitui a natureza da substância mental. Pois nesta concepção tudo o que pode ser atribuído ao corpo pressupõe a extensão e todas as propriedades mentais não são nada mais do que diferentes maneiras de pensar e, logo, dependem da substância pensante.

Para que a distinção entre res extensa e res cogitans faça sentido no sistema cartesiano, é necessário supor que a alma seja uma substância completamente diferente da matéria, e que a razão, quando bem utilizada pelo ser que pensa, pode levá-lo ao conhecimento de verdades, tais como a da existência do eu e de Deus. Logo, ela não pode se encontrar de forma parcial nos seres irracionais, que não possuem consciência de tais verdades. Esses são condicionados pela matéria a simplesmente procurar o que lhes agrada e evitar o que lhes causa dor? ${ }^{9}$.

Assim, Descartes julga ter colocado uma "diferença de espécie" entre o homem e os animais, afastando-se desta forma tanto da hipótese de Montaigne e Charron quanto da dos 
aristotélicos (Descartes 7, p. 46). Os céticos teriam chegado a suposições extremas ao afirmarem não só que nós raciocinamos de modo semelhante ao animal, mas que os animais inclusive nos superam em muitas coisas. Descartes protesta dizendo que o fato dos animais terem sentidos mais desenvolvidos que os nossos não prova que eles têm uma alma superior à nossa, pois nesse caso agiriam melhor em tudo. O mesmo raciocínio pode ser aplicado à observação dos relógios, que podem medir o tempo com mais precisão do que nós, embora sejam feitos apenas de rodas e molas (Descartes 7, p. 59).

A partir de Descartes, as analogias entre animal e mente humana passaram a ser menos frequentes entre os estudiosos que, em vez disso, começaram a fazer comparações entre animal e máquina, como mostra Harrison (12). O homem, enquanto substância pensante, diferiria de ambos. Por outro lado, devemos nos lembrar que "máquina" nesse caso não corresponde apenas a objetos mecânicos, mas também ao próprio homem enquanto matéria corporal e, nesse sentido, o homem, ao menos em parte, se aproximaria da espécie animal.

\section{A posição de Hume}

Depois de formulada e divulgada a hipótese de Descartes, o debate se intensificou, tanto em quantidade como em qualidade: uns mais próximos do seu raciocínio com relação à hipótese mecanicista, como Malebranche, outros atacando-o, como Locke e Hume.

Para Locke $^{10}$, os animais possuem algum tipo de raciocínio, mas de ideias particulares apenas e não têm o poder de fazer abstrações e generalizar ideias, uma vez que eles não utilizam palavras ou quaisquer sinais gerais. Eles são dotados, portanto, de razão, embora de uma inferior à dos homens. Hume escreve de modo muito próximo a Locke e dedica pelo menos três seções do Tratado da Natureza Humana e uma seção da Investigação sobre o Entendimento Humano para discutir questões relacionadas à razão dos animais.

Como nota Chibeni (6), Hume não direcionou sua filosofia para atacar a tese dos animais-máquinas, mas sem dúvida esse era um dos seus alvos. O propósito de Hume, continua Chibeni, é o de demonstrar que a sua teoria a respeito do hábito é aplicável também aos animais: tomando como pressuposto o fato de que os animais não são dotados 
de raciocínios abstratos e demonstrativos, percebe-se, no entanto, que fazem inferências causais e, logo, agem por algum mecanismo da imaginação denominado de hábito ou costume, que corresponde a uma espécie de "raciocínio experimental" (13, p. 105), e não pela razão abstrata.

Para Hume, todas as conclusões da nossa ciência experimental precisam estar apoiadas em uma forma de analogia: o que se observa a respeito de um ser animado deve se estender aos demais (Hume 13, p. 105). Os animais, assim como os homens, vão aprendendo, desde o nascimento, com a experiência. De causas semelhantes, eles derivam efeitos semelhantes. Assim, quanto mais velho for o cão, o cavalo ou o pássaro, mais conhecimento terão eles adquirido a respeito dos eventos naturais.

Hume nos fornece vários exemplos para que se possa mensurar o nível de sagacidade dos animais. O primeiro é de que os animais aprendem com a experiência: "um cavalo, acostumado ao campo, torna-se ciente do seu próprio peso antes de saltar e nunca tentará o que excede sua força e habilidade. Um velho cão de caça deixa a parte mais fatigante da caça ao mais jovem, e se posicionará ao encontro da lebre na volta" (Hume 13, p. 105). No Tratado, ele ainda cita o exemplo do cão que evita o fogo e o precipício, que rosna para estranhos e que cuida do seu dono, como sendo ações “de natureza vulgar" dos animais. Além dessas, ele comenta sobre os casos "mais extraordinários de sagacidade", que são as relacionadas à sua própria preservação e à propagação da espécie. O exemplo citado por Hume para ilustrar esse nível de sagacidade é o do pássaro, que muito cuidadosamente escolhe o material para construir o seu ninho e que, na estação apropriada, choca seus ovos “com toda precaução de que um químico é capaz” (Hume 14, p. 177).

Visto que os animais não utilizam a razão abstrata ${ }^{11}$ para fazer inferências a partir da experiência e procedem da mesma forma que as crianças e até mesmo os filósofos nas suas vidas cotidianas, Hume supõe que nossas ações são reguladas por um princípio natural, diferente da razão especulativa, que nos leva a inferir os efeitos das suas causas. Esse princípio, denominado de costume ou hábito, começa pela observação da regularidade dos fenômenos sensíveis e, por meio da imaginação, leva os animais e a humanidade a inferirem os eventos que se seguirão desses. O hábito age como um guia no decorrer da nossa vida em favor da preservação da espécie, pois, se fôssemos guiados somente pela 
razão, apenas os filósofos ou aqueles que raciocinam bem sobreviveriam neste mundo (Hume 13, p. 106).

Ao fazer a distinção entre a razão, que teria por finalidade encontrar certezas de caráter demonstrativo, e os raciocínios causais ou experimentais, Hume limita a "extensão do conhecimento", como diz Chibeni, e diverge de Locke, que não observara tais diferenças. Dessa forma, o conhecimento demonstrativo ou a priori em Hume, além de não ser objeto de reflexão do animal, também não se constitui em fundamento necessário para a preservação da espécie humana. Mas, pelo processo de análise analógico, tanto a espécie humana quanto a animal refletem e agem sob o mesmo processo de ação e reflexão concedido pela natureza. Por um lado, portanto, percebe-se que há em Hume uma aproximação do modo de pensar do homem ao animal e, nesse sentido, ao pensamento dos céticos modernos. Por outro, devido à distinção entre razão pura e raciocínios experimentais promovida por Hume, os animais são mais limitados do que o homem na sua forma de conhecer, embora isso não pareça representar uma diferença de espécie entre os seres animados.

\section{Hume e os céticos modernos}

Os exemplos e argumentos que Hume levanta em favor da hipótese da razão dos animais são visivelmente inspirados na tradição filosófica. Entre os céticos modernos, sabese que Hume leu pelo menos Montaigne ${ }^{12}$, mas não há indícios de que tenha consultado diretamente Charron ou La Mothe Le Vayer (a não ser, pelo menos, via Pierre Bayle). No entanto, podemos realizar aqui um paralelo entre os seus argumentos e de todos esses autores. Mas, antes disso, não podemos deixar de mencionar o filósofo cético que mais influenciou Hume, Pierre Bayle, particularmente acerca do que ele fala a respeito da razão dos animais.

No seu Dicionário, verbete "Jerôme Rorarius", Bayle expõe argumentos para contrapor as suposições cartesiana e aristotélica de que os animais sejam destituídos de razão. Logo no início, levanta um exemplo parecido com o de Hume e de Montaigne sobre os cuidados que o cão tem para com seu dono, ao informar que, de acordo com Rorarius, os cães procuram guardar o seu dono de perigos e, se for o caso, até vingam a sua morte (nota 
B). Um pouco antes, na mesma nota, cita um exemplo dos aristotélicos destinado a comprovar que os animais agem de forma mecânica: o cão deixa de tocar num pedaço de carne quando vê o seu dono o ameaçar com um bastão. Mas percebe que, para que esse caso faça sentido, é preciso considerar que a ação do cão seja acompanhada de conhecimento, pois

é necessário que ele se lembre dos golpes que recebera e porque os recebeu; é necessário que ele saiba que, se ele se precipitar sobre o prato de carne que se impõe aos seus sentidos, a mesma ação se seguirá na qual ele apanhou, e ele conclui que, para evitar novos golpes de bastão, ele deve se abster daquela carne. Não é isso um verdadeiro raciocínio? ${ }^{13}$ (Bayle 2, tomo IV, p. 76).

Hume faz um comentário semelhante, também para mostrar que os animais são capazes de fazer predições: “é necessário, em primeiro lugar, que exista alguma impressão imediatamente presente na sua memória ou sentidos, para ser o fundamento dos seus juízos. Do tom de voz o cão infere a raiva do seu dono e prevê a sua própria punição" (Hume 14, pp. 177-8).

Mas, embora apresente objeções à doutrina dos autômatos, Bayle não propõe, como Hume, um método baseado na observação experimental a fim de explicar o processo de raciocínio das criaturas animadas. O propósito das notas citadas do artigo "Rorarius" é o de mostrar as fraquezas das doutrinas que debatem sobre a razão aos animais ${ }^{14}$.

Ainda no artigo "Rorarius" nota F, ao discutir as ideias do teólogo Théophile Raynaud, Bayle observa que é falso demarcar o homem do animal com base no livrearbítrio como pretende o jesuíta, senão seríamos obrigados a afirmar, da mesma forma, que a alma de uma criança é de natureza diferente da alma de um adulto, já que ela não raciocina como nós e, logo, não é dotada de livre-arbítrio. O motivo pelo qual os animais não raciocinam como nós, ele explica, deve-se ao fato de que os seus sentidos não se assemelham aos nossos, pois se, pelo contrário, a nossa alma estivesse no corpo deles certamente teria as sensações que eles têm. A alma de um cão em Aristóteles pensaria nos universais, suas conclusões indicam na nota $\mathrm{E}$.

Em Descartes, o problema da condicionalidade da razão ao corpo não altera o estatuto da alma. E de nada adianta os animais possuírem órgãos aptos para determinadas tarefas se suas almas são diferentes da nossa, pois mesmo que as pegas e os papagaios tenham órgãos que os possibilitem a emitir sons, isso não significa que consigam organizar um discurso 
coerente ou raciocinar sobre os sinais que emitem, diz ele no Discurso do Método, quinta parte.

Montaigne adota outro tipo de procedimento para analisar as expressões dos animais: quando observa que esses se comunicam por gestos e tons de voz da mesma forma que a criança, parece se apoiar numa análise do tipo analógica, que é a da observação dos seus comportamentos e compará-los com os nossos. Sexto Empírico faz o mesmo quando levanta a possibilidade de que os cães possuam linguagem: ele solicita que se observe a uniformidade dos sons que o animal emite e compara a sua linguagem aparentemente incompreensível com a dos bárbaros ou estrangeiros.

Mas esta forma de investigação, cara a Hume, encontra-se apenas implícita entre os céticos. Hume deixa claro que a sua filosofia tem como ponto de partida o procedimento analógico, que nos leva a esperar causas semelhantes das já observadas. No segundo parágrafo da seção XII, do livro II, parte I do Tratado, ele diz que a sua proposta de investigação é similar à dos anatomistas: esses observam que a estrutura corporal humana é semelhante à do animal (especialmente os mais nobres) e inferem que, se a operação de suas partes é a mesma, as causas dessa operação também serão as mesmas. Similarmente, para tratar da questão do amor e ódio dos animais, a sua "anatomia da mente" teria como propósito primeiro observar a correspondência entre as paixões nos homens e nos animais para então verificar as suas causas comuns.

Ainda nessa seção, ele diz que os animais não cultivam amor apenas entre os seres da mesma espécie que a sua, mas que essa afeição se estende aos homens e aos animais de espécies diferentes. O uivo e as lamentações do cão produzem preocupações em seus companheiros, é um dos seus exemplos para o primeiro caso. E, logo depois, afirma que os cães são mais motivados quando caçam em bando do que quando estão sós, e considera isso um sinal evidente da presença do sentimento de simpatia entre eles. Há ainda casos de associação entre animais de espécies diferentes, como os bois, que se unem aos cavalos em busca de companhia. Por fim, certos animais como os cães demonstram seus sentimentos com relação aos homens: se os tratamos bem, recebemos sua afeição e carinho, se os tratamos mal, temos como contrapartida seu ódio e rancor (Hume 14, pp. 397-8).

Na seção "Do orgulho e humildade dos animais" desse mesmo livro do Tratado, Hume mostra que há sinais de orgulho e humildade entre quase todas as espécies. O 
orgulho geralmente tende a destacar a sua beleza, como se vê no andar do cisne e do pavão, no canto do rouxinol, na velocidade dos cavalos, no olfato dos cães, na força do touro e do galo (Hume 14, p. 326). As espécies que se aproximam do homem, além disso, demonstram orgulho quando são elogiadas, o que parece ser um sinal claro de que são suscetíveis a essas paixões.

Montaigne também encontra sinais de amor, ciúme, malícia, avareza e até de fidelidade conjugal entre os bichos, pois eles se unem apaixonados, choram como nós, sabem economizar o alimento quando necessário, confiam uns nos outros e, assim como os homens, os machos se associam a uma ou a mais fêmeas, dependendo da espécie (Montaigne 20, p. 265 e 269).

Além dos exemplos vulgares, Montaigne também levanta casos de sagacidade "mais extraordinária”, como diz Hume, que envolvem a sua própria preservação e propagação da espécie. Assim como Hume, Montaigne comenta sobre o modo como os pássaros constroem suas moradas. Montaigne e também Le Vayer admiram-se com a organização social de alguns animais, como as abelhas e Sexto Empírico chegou a supor que o cão tenha noções de justiça e seja dotado de virtude, valentia e inteligência.

Com relação à organização social, virtude e sentimentos dos animais, porém, Hume é um pouco mais comedido do que seus antecessores céticos. Em vez de simplesmente mostrar o quanto o pensamento deles se aproxima do nosso, ele demarca mais nitidamente que os animais, embora sejam dotados de razão como nós, são mais limitados em sua capacidade. Os animais têm pouco ou nenhum sentido de virtude e são incapazes de formar ideias sobre direito e propriedade, perdem facilmente as noções de relações sanguíneas, e as suas atribuiçõoes de orgulho e humildade se estendem aos seus próprios corpos somente, e nunca às suas próprias mentes ou aos objetos externos (Hume 14, p. 326). Na seção sobre amor e ódio dos animais, ele acrescenta que os bichos são pouco suscetíveis aos prazeres e dores da imaginação e só podem julgar os objetos pelo bem ou mal sensível que eles próprios produzem (14, p. 397).

Como apresentado acima, para Montaigne e para Sexto, as formigas e pássaros podem até prever acontecimentos futuros. Montaigne conjectura que os atuns tenham conhecimento de geometria, aritmética e astronomia, e Charron, que os bichos saibam 
somar, dividir e extrair os universais a partir dos particulares. Montaigne e Le Vayer, por fim, chegam a levantar a hipótese audaciosa de que alguns animais têm religião ${ }^{15}$.

Hume, ao distinguir o conhecimento demonstrativo do experimental, acaba limitando a sua extensão, negando aos animais tais capacidades abstratas, talvez por serem desnecessárias para a sua sobrevivência. Por outro lado, ele mostra no ensaio "O Estóico" que os brutos têm muitas de suas necessidades supridas pela natureza, sendo cobertos e armados por ela, como mostra D. Boyle (4). O argumento se encontra também em Montaigne, mas com o propósito de enfatizar as vantagens do animal com relação ao homem: couros, escamas, dentes afiados e chifres são apenas alguns dos recursos fornecidos pela natureza aos animais e que não se encontram no homem (Montaigne 20, p. 255).

Hume também atribuiu uma espécie de sabedoria universal à natureza, a fim de fornecer uma explicação para questões que não poderiam ser fornecidas pela filosofia. Assim como seus antecessores céticos, ele pretende mostrar que não só os animais irracionais, mas mesmo camponeses iletrados e bebês se aperfeiçoam pela experiência e adquirem conhecimento. No entanto, esse conhecimento não nos é concedido pela razão abstrata, ele acrescenta, pois se fosse assim, jamais um bebê aprenderia com a experiência, como acontece àquele que, tendo queimado a mão ao colocá-la na chama de uma vela, passa a se afastar de qualquer outra vela (Hume 13, p. 39). Nem os próprios filósofos teriam sobrevivido se tivessem sido governados pelos princípios da razão pura ${ }^{16}$. A natureza jamais deixaria aos cuidados dos metafísicos a tarefa de descobrir os princípios de causa e efeito por meio de raciocínios abstratos e sofisticados, ou seja, esses jamais poderiam fornecer argumentos baseados na razão para fundamentar as nossas inferências causais. O processo de conhecimento que adquirimos da experiência, portanto, em vez da razão, deve-se a um princípio da imaginação que Hume denomina costume ou hábito. O hábito também é um instinto concedido pela natureza que nos permite guiar as nossas ações diárias e fazer inferências, como a de que objetos e acontecimentos futuros deverão se assemelhar aos objetos e acontecimentos que presenciamos no passado (Hume 13, p. 106$8)$.

Montaigne louva a sabedoria e o modo de vida dos artesãos e lavradores, pois esses estão mais próximos da natureza, que é para ele o nosso guia. Os animais e as crianças 
também conservam uma espécie de pureza intelectual, visto não estarem totalmente contaminados pela razão artificial. Charron segue Montaigne nesta leitura. Em Hume, o apelo à natureza aparece nesse contexto para esvaziar os discursos fundados na razão abstrata e reforçar a sua teoria de que as espécies humana e animal submetem-se, em última instância, a um instinto natural. Não há aqui um retorno cego à natureza em busca de um guia para os procedimentos humanos; porém encontramos em Hume a necessidade de consultar a natureza como forma de se afastar das teorias especulativas que teriam deixado de cumprir esse requisito. Para esse fim, aqui, como em Montaigne e Charron, a natureza humana e animal são aproximadas. A própria razão, diz Hume, "não é mais do que um extraordinário e ininteligível instinto em nossas almas” (Hume 14, p. 179). Montaigne dá sinais de semelhante conclusão, quando questiona a ideia de que os animais agiriam por "inclinação natural” enquanto os homens por razões e vontades próprias: os meios artificiais que encontramos para nos proteger são derivados de um "instinto ou preceito natural", assim como se observa no elefante, no touro, no javali, no mangusto (Montaigne 20, pp. 256-7). Entretanto, há graus de distância entre seus pensamentos: Montaigne faz uso desse argumento especialmente para atacar a vaidade humana e sua pretensão de dominar os demais seres fazendo uso da razão; enquanto que Hume usa a noção de instinto para a elaboração de um novo estudo sobre a natureza humana sem negligenciar suas paixões e ações condicionadas pela natureza, além da razão abstrata.

Hume promove a relação sistemática entre natureza humana e animal e vincula o tópico da racionalidade dos animais ao da sua concepção de natureza humana. Como crítico do sistema cartesiano, ele pretende mostrar que, tanto o homem quanto o animal aprendem e se desenvolvem a partir da experiência que eles têm com o mundo externo; ao passo que o propósito dos céticos antecessores de Descartes e críticos dos escolásticos é o de mostrar principalmente que o homem não é uma criatura superior aos animais.

Por outro lado, a filosofia de Hume pode ser aproximada à de Montaigne, Charron e Le Vayer no que diz respeito ao desprezo da razão metafísica (seja a aristotélica ou cartesiana), à aproximação do homem e do animal à natureza e à formulação de um ceticismo com relação a tudo o que ultrapassa os limites da sua investigação. Enquanto em Descartes existe a pretensão de edificação da razão como propriedade específica da humanidade, em Hume e nos céticos renascentistas há a necessidade de destronar a razão 
humana, deslocando o homem do centro do universo e levar em consideração outras formas de entendimento e concepção da realidade presentes em outros seres, a fim de demarcar suas oposições aos sistemas que privilegiam o homem em relação ao animal irracional.

\section{REFERÊNCIAS BIBLIOGRÁFICAS}

1. ARAÚJO, H. F. Relação corpo-alma, no De anima, de Aristóteles.Revista F@fic, V. 1, p. 91-98, 2010.

2. BAYLE, Pierre. Dictionnaire historique et critique. Paris: Aupelf/Cnrs, 1972. Verbetes "Pereira, Gomezius" e "Rorarius, Jerôme".

3. BOUILLIER, Francisque. Histoire de la philosophie cartésienne. Paris: C. Delagrave, 1868. vol. I.

4. BOYLE, Deborah. Hume on Animal Reason. In: Hume Studies, Volume XXVIX, Number 1 (April, 2003), pp. 3-28.

5. CHARRON, Pierre. De la sagesse. Paris: Chaignieau, 1797.

6. CHIBENI, S. S. Hume e a razão dos animais. Coleção CLE, 2013. No prelo.

Disponível em: http://www.unicamp.br/ chibeni/public.htm

7. DESCARTES, René. Discours de la Méthode. In: Oeuvres de Descartes. Paris, Leopold Cerf, 1902. Ed. Charles Adams \& Paul Tannery. Vol. VI.

8 . . Les Passions de L’âme. In: Oeuvres de Descartes. Paris, Leopold Cerf, 1909. Ed. Charles Adams \& Paul Tannery. Vol. XI.

9. EMPIRICUS, Sextus. Outlines of Pyrrhonism. Cambridge: Cambridge University Press, 2007. Ed. Julia Annas \& Jonathan Barnes.

10. GASSENDI, Pierre. Dissertations en forme de paradoxes contre les aristotéliciens. Paris: J Vrin, 1959.

11. HARRISON, Peter. Descartes on Animals. In: The Philosophical Quarterly, Vol. 42, No. 167 (Apr., 1992), pp. 219-227.

12. . The Virtues of Animals in Seventeenth-Century Thought. In:

Journal of the History of Ideas, Vol. 59, No. 3 (Jul., 1998), pp. 463-484.

13. HUME, David. Enquiries Concerning Human Understanding. Oxford: Clarendon, 1975. Edit. Selby-Bigge, rev. P. H. Nidditch. 
14. . A Treatise of Human Nature. Oxford: Clarendon, 1978. Edit. Selby-

Bigge, rev. P. H. Nidditch.

15. LA MOTHE LE VAYER, François de. Opuscule ou petit traité sceptique sur cette commune façon de parler: n'avoir pas le sens commun. Paris: A. de Sommaville, 1646.

16. . Soliloques Sceptiques. Paris: Louïs Billaine, 1670.

17. . Cinq dialogues faits à l'imitation des anciens \& Quatre autres

dialogues du mesme auteur. Francfort: Jean Sarius, 1716. 2 vol.

18. . Discours pour montrer que les doutes de la philosophie sceptique sont de grand usage dans les sciences. In: Oeuvres complètes. Paris: Aupelf, 1757.

19. LOCKE, John. An essay concerning human understanding. Oxford: Clarendon, 1979.

20. MONTAIGNE, Michel de. Essais. Paris: Lefevre, 1834.

21. NEWMYER, Stephen T. Speaking of Beasts: The Stoics and Plutarch on Animal Reason and the Modern Case against Animals. In: Quaderni Urbinati di Cultura Classica, New Series, Vol. 63, No. 3 (1999), pp. 99-110.

22. ROCHA, Ethel. Animais, homens e sensações segundo Descartes. In: Kriterion, Belo Horizonte, nº 110, Dez/2004, p. 350-364.

\title{
REASON OF ANIMALS IN HUME AND IN THE MODERN SKEPTICS
}

\begin{abstract}
David Hume can be compared to the modern skeptics in many aspects. Concerning the topic of reason of animals, Hume seems to follow closely the ideas of some modern skeptics and keeps considerably distance from Descartes's thinking about it. Moreover, unlike philosophers like Montaigne, Charron and La Mothe Le Vayer, Hume had not intended to put the human rationality at a level close to the animals to prove the weakness of the intellect human. Hume wanted compare our way of thinking to the animal thinking to give a more accurately support to his ideas about human nature. In this article I will analyze how the first skeptics of modernity faced the topic of reason of animals and compare these with the ideas of Hume on the subject. I also will mention the contributions of Descartes and Pierre Bayle about the subject.
\end{abstract}

Keywords: scepticism, reason of animals, Hume, Descartes, Montaigne.

\section{NOTAS}

\footnotetext{
${ }^{1}$ Conforme Harrison (11 e 12). Não entro aqui na controvérsia de se Aristóteles defendia ou não um dualismo com relação à alma e corpo. Uma opinião contrária à tese do dualismo aristotélico encontra-se em Araújo (1).

${ }^{2}$ Para alguns, contudo, a ênfase na irracionalidade dos animais é incompleta com relação à totalidade do pensamento estóico a esse respeito. Ver, por exemplo, Newmyer (21). Uma explicação dos pensamentos dos antigos e modernos a esse respeito encontra-se no artigo "Gomes Pereira" do Dicionário Histórico e Crítico de Pierre Bayle, nota E e "Jerôme Rorarius", notas C, D e K.
} 
${ }^{3}$ Conforme o Dicionário de Bayle, verbete "Charron", nota B.

${ }^{4}$ Sobre isso, Montaigne se expressa do seguinte modo: nunca um leão foi servo de outro nem o cavalo teve que se submeter ao seu semelhante, por pura maldade (faulte de coeur) (20, p. 258).

${ }^{5}$ Esse exemplo também está em Montaigne (20, p. 265).

${ }^{6}$ E para Gassendi, enquanto o homem modifica e transforma tudo o que come, os animais apenas fazem uso de alimentos naturais e adaptados à sua natureza e, assim, vivem mais conformes ao meio em que nasceram (10, p. 448).

7 A defesa de que os animais são dotados de linguagem e de um conceito elementar de justiça pode ser encontrada também em Plutarco, entre os antigos (ver Newmyer 21).

${ }^{8}$ Os espíritos animais são como "um vento muito sutil ou uma chama muito pura e viva" que sai do cérebro por meio dos nervos, conforme o Discurso do Método (7, p. 54), Quinta Parte e As Paixões da Alma, parte I, art. 7.

9 Alguns sustentam a visão de que a tese cartesiana implica na ideia de que os animais são incapazes de sentirem dor e prazer, ou seja, de que eles não têm sensações (ver, por exemplo, Rocha 22). Mas, segundo Harrison (11), essa tese aparece explicitamente em Malebranche e em outros cartesianos, não em Descartes. Harrison segue Cottingham ao mostrar que, embora Descartes tenha insistido na ideia de que os animais não tenham pensamento e auto-consciência, nenhuma dessas asserções o compromete com a tese de que animais não sentem.

${ }^{10}$ Ensaio sobre o entendimento humano livro II, cap. XI, sec. 10 e 11.

${ }^{11}$ Uma vez que os animais não são dotados de raciocínio abstrato e demonstrativo para Hume, Tom Beauchamp supõe que exista aqui uma diferença de espécie, e não de grau, entre a razão humana e animal. Deborah Boyle, porém, defende que em Hume, os animais têm a mesma habilidade que os seres humanos, e que apenas seus poderes de atenção e observação são inferiores e, por isso, não se dedicam a raciocínios demonstrativos. Ela nos lembra ainda que na seção sobre a razão dos animais na Investigação, Hume insere uma nota de rodapé listando nove maneiras nas quais o raciocínio de uma pessoa pode ser melhor do que de outra e adverte que, compreendendo estas diferenças entre seres humanos (de grau, portanto), será fácil entender a razão da diferença entre homens e animais, que supostamente seria do mesmo tipo (BOYLE 4).

${ }^{12}$ Hume cita Montaigne no ensaio "O Cético" e faz referência a um exemplo seu presente na "Apologia", conforme mostrei na minha tese de doutorado, pp. 69-70, disponível em http://www.teses.usp.br/teses/disponiveis/8/8133/tde-10122010-105833/es.php. As leituras que Hume fez de Bayle encontram-se nas págs. 75-6 da mesma tese.

${ }^{13}$ No original: “il fault qu'il se souvienne \& des coups qu'on lui a donnez \& pourquoi il les a reçus: il faul qu'il connoisse que s'il se ruoit sur le plat de viande qui frappe ses sens, il seroit la même action pour laquelle on l'a battu \& qu'il conclue que pour éviter des noveaux coups de bâton, il doit s'abstenir de cette viande. N'est-ce pas un véritable raisonnement?".

${ }^{14}$ A posição pessoal de Bayle sobre o assunto é complexa. No artigo, aparentemente ele se limita a atacar as doutrinas consagradas dos filósofos, a saber, a aristotélico-escolástica, a cartesiana (principalmente nas notas B, E e F) e a de Leibniz (notas H e L), mas quando apresenta os que defendem a racionalidade dos animais (notas D e K), incluindo Montaigne e Charron, não levanta objeções. Na nota B, por exemplo, ele termina por considerar toda essa disputa com os cartesianos uma perda de tempo (peine perdue). No entanto, é possível que o propósito do artigo seja meramente o de enfatizar as opiniões de Rorarius sobre a razão dos animais e mostrar as contradições dos outros sistemas. Bouillier, por exemplo, interpreta Bayle como mantendo o juízo em suspenso diante dessa questão (3, p. 163). Conforme colocado acima, La Mothe Le Vayer também poderia ser outro cético a entrar nessa categoria, visto que a maioria dos seus debates termina na suspensão completa do juízo acerca de todas as questões. Com relação à razão dos animais, porém, o único trecho que encontrei no qual o autor se limita a meramente descrever as opiniões sobre o assunto (sem se servir, para seus fins, da hipótese de que os animais tenham alguma racionalidade) está no "Diálogo da ignorância louvável" e, mesmo aqui, quando apresenta a hipótese estóica, acaba zombando dela, por considerar os seus adeptos persuadidos, assim como os ratos, de estarem no centro do universo, conforme mostrado acima. E, logo depois dessa, termina a discussão apresentando trechos das Sagradas Escrituras e da Suna de Maomé em defesa dos animais (17, tomo II, p. 98-100). Em Montaigne, Charron e Gassendi não encontrei passagens que mostrassem os dois lados da questão sem o uso da hipótese da razão dos animais em favorecimento dos seus ceticismos.

${ }^{15}$ Bayle, no artigo "Rorarius", nota D, mostra que muitos antigos já defendiam que os animais têm religião, contudo, na nota $\mathrm{C}$ ele apresenta a opinião cartesiana dos animais-máquinas como a que mais beneficia a fé, “embora seja tão difícil de sustentá-la". De fato, no Discurso do Método, Descartes afirma que a tese de que 
os animais possuem alma desvia "os espíritos fracos do caminho reto da virtude", de modo que nada mais poderíamos esperar, depois desta vida, senão o mesmo fim que as moscas e formigas (7, p. 59). Ainda na nota $\mathrm{C}$, Bayle diz que a teoria contrária, isto é, a de que os animais têm sentimentos, invalidaria a teoria do pecado original (Bayle compreende aqui a teoria cartesiana como não concedendo sentimentos aos animais). Pois, se essa teoria tem como principais provas a doença e a morte, como conceder que os bichos adoecem e morrem mas não pecam?

${ }^{16}$ É importante aqui fazer uma comparação com Gassendi. Nos seus ataques aos aristotélicos, ele considera a razão pura dialética natural, enquanto a artificial é a das escolas. Pois, se a lógica utilizada em seu tempo fosse a única possível, então crianças, gente inculta ou mesmo de boa condição, embora contrária à dialética, jamais poderia analisar ou prever as consequências das coisas que observam (10, pp. 234-6 e 254). Gassendi ataca a dialética aristotélica, que considera artificial, e apela à natural, que estaria presente em todo ser humano, a qual a noção de causalidade faria parte. Hume, como visto, atribui a noção de causalidade ao costume, que seria uma espécie de raciocínio, embora gradativamente diferente da razão abstrata. 